2 O'Grady J. Psychiatric evidence and sentencing: ethical dilemmas. Crim Behav Ment Health 2002; 12: 179-84.

3 Rix KJB. Medico-legal work of psychiatrists: direction, not drift. Commentary on ... 'You are instructed to prepare a report'. Psychiatrist 2011; 35: 272-4.

Tom Clark, Consultant Forensic Psychiatrist and Training Programme Director, Reaside Clinic and Rampton Hospital, Birmingham, UK, email: Thomas.Clark@bsmhft.nhs.uk; Ramneesh Puri, Consultant Forensic Psychiatrist, Reaside Clinic and Rampton Hospital, Birmingham doi: $10.1192 / p b .35 .11 .431 a$

\section{Mephedrone as a cognitive enhancer and its kinship to khat}

The report on the adverse effects of mephedrone in patients presenting to an acute service in Scotland echoed many of our own findings in attendees of a service aimed at the early detection of psychotic illness based in inner-city London. ${ }^{1}$

In a small sample, we found that $8 \%$ of patients $(n=5)$ seeking help for concerns about their mental health were using mephedrone. They reported using the drug for recreational reasons (during activities such as clubbing) and simply out of curiosity. Four out of the five patients stated that they also used mephedrone as a cognitive and performance enhancer to aid them in their studying and to help them stay awake while at university or college. They explained that it was a cheap and accessible alternative to other stimulants: one dose of $200 \mathrm{mg}$ costs $E 2-3$.

As mephedrone has now been classified as an illicit substance, it is possible that similar (currently unclassified) chemical compounds will become more widely used as cognitive enhancers in the student population. Both acute secondary and primary care mental health services should be aware of the adverse effects of this group of stimulants.

It is interesting to note that mephedrone is a semisynthetic form of cathinone, the drug found in the East African herb khat. The chewing of khat has a long history and the drug continues to be used legally within several immigrant populations in Britain. Understanding the adverse effects of mephedrone has allowed us to appreciate the adverse consequences of khat misuse - a problem that has provoked substantial debate previously. ${ }^{2}$

1 Mackay K, Taylor M, Bajaj N. The adverse consequences of mephedrone use: a case series. Psychiatrist 2011; 35: 203-5.

2 Warfa N, Klein A, Bhui K, Leavey G, Craig T, Stansfeld SA. Khat use and mental illness: a critical review. Soc Sci Med 2007; 65: 309-18.

Karl H. Marlowe, Consultant Psychiatrist and Honorary Senior Lecturer, East London NHS Foundation Trust, UK, email: karl.marlowe@ eastlondon.nhs.uk; Henrietta Mbeah-Banks, Mental Health Nurse, East London NHS Foundation Trust

doi: $10.1192 / p b .35 .11 .432$

\section{If not now, when ... ?}

The contrast between the cover of the August issue of The Psychiatrist and the content of the related article ${ }^{1}$ could hardly have been greater. On the outside: shocking depiction of a winged Freud in drag - women's bathing costume, high heels - flanked by the sphinx. Inside: announcement of change of job title from 'consultant psychotherapist' to 'consultant medical psychotherapist', buttressed by bland reassurance that 'the working role of most medical psychotherapists has become more like that of other consultant psychiatrists' and that warfare between different therapeutic modalities has ceased, and predictable pleas for greater recognition and investment in medical psychotherapy.

Sadly, it's the cover that gets it right. Medical psychotherapy is a chimera trying awkwardly to reconcile two currently incompatible sets of values - medical instrumentalism and psychotherapeutic humanism. A change of name will do nothing to resolve medical psychotherapy's abiding dilemma: how to stay true to psychotherapeutic values without isolationism or, claiming a spot in the mainstream, undermining its case for a separate identity.

I would like to see medical psychotherapy accepting the full irony and challenge of its chimeral status: a 'hopeful monster', ${ }^{2}$ ensuring on the one hand that psychiatry does not become increasingly confined to pharmacology and forensics, and on the other that psychotherapists keep sight of their prime task - contributing to the effective treatment of psychological illness.

But nature abhors a chimera. Cash-strapped chief executives are unlikely to fall in with medical psychotherapy's vague promises when they can get NICE-approved therapies delivered by bureaucracy-savvy clinical psychologists and nurse specialists at half the price.

Which brings us back to Mace $\&$ Healy's seemingly proud statement that medical psychotherapy is unique among the CCT-bearing specialties in being 'not descriptive of the types of patients seen'. But therein lies its great weakness. Despite today's name-change, the rose will smell as uncompelling until the Faculty of Medical Psychotherapy becomes the Faculty of Personality Disorders and Complex Cases. Then at last the unique skills of the medical psychotherapist really will be seen as indispensable, and Mace \& Healy's legacy come to fruition. Yesterday's hopeful monster may yet become tomorrow's rolemodel: the psychotherapeutically sensitive psychiatrist.

1 Mace C, Healy K. Medical psychotherapy: a speciality for now. Psychiatrist 2011; 35: 301-4.

2 Gould SJ. The Structure of Evolutionary Theory. Harvard University Press, 2002.

Jeremy A. Holmes, Visiting Professor of Psychotherapy, Exeter University, UK, email: j.a.holmes@btinternet.com

doi: $10.1192 / p b .35 .11 .432 a$

\section{Psychological therapies for bipolar disorder: addressing some misunderstandings}

We would like to reply to the letter published in your journal by Gupta \& Brown, ${ }^{1}$ concerning a recent British Psychological Society report on understanding bipolar disorder. ${ }^{2}$ As authors of that report, we were pleased that it has generated debate. In the main, responses from psychiatric and other clinical colleagues have been overwhelmingly positive: MDF The Bipolar Organisation referred to the report as 'groundbreaking' ${ }^{3}$ and Stephen Fry's tweet on the report led to 2000 downloads in one day. 
We thank Drs Gupta and Brown for their interest in this report, and for giving their opinion. However, they make some criticisms that we feel are based on misunderstandings, and we would like to correct these. In contrast to the view of Gupta \& Brown, the report does not present an antipsychiatry position: its explicit purpose is to provide a psychological perspective to supplement the existing literature, which is predominantly based on a biological perspective. The report does discuss the limitations of formal mental health diagnoses, but recognition of these limitations is not discipline specific. In our experience, individuals who have been told they have bipolar disorder are rarely informed about the explanatory and predictive limitations of this diagnosis. By outlining these in our report, we aim to raise awareness that the construct of diagnosis is a subject of debate, and therefore that it may be legitimate to explore alternative means of understanding experiences that are classified in this way. Gupta \& Brown propose that diagnoses in mental health are based on specific scientific data about aetiology. We would contest this. Indeed, this is even explicitly spelled out in DSM-IV-TR, ${ }^{4}$ which states that recent versions of the DSM 'attempt to be neutral with respect to theories of aetiology' ( $p$. xxvi). The authors claim that we do not offer an alternative to diagnostic systems. This is not the case with regard to either the descriptive or the explanatory function of diagnoses. As regards the former, we propose that normal English is sufficient (for example, the report uses 'a tendency to experience extremes of mood') and avoids some of the more unhelpful side-effects of psychiatric diagnosis such as stigma. As regards the latter, we propose that this is in any case limited and that individualised multifactorial formulation, where professional and service user work together to identify the various factors contributing to the problem, offers a more useful approach.

We do not claim that bipolar disorder is a lifestyle choice and we do not argue that psychological interventions alone are a preferred solution for all individuals with a diagnosis of bipolar disorder. We do, however, argue (consistent with NICE guidelines ${ }^{5}$ ) that more people should have access to psychological interventions and that these can improve outcome for some people. Systematic reviews support the benefits of structured psychological approaches, particularly in relation to reduction of relapse risk. ${ }^{6,7}$ We do not argue against the use of medication treatments, but we do discuss the fact that they are not necessarily helpful for everyone and that choice in relation to this, as well as other forms of treatment, is an important consideration. We accept that the evidence for psychological interventions is based mainly on participants who are currently receiving medication as well. This could mean that the sole ingredient offered by psychological interventions is an increase in adherence, but this is no more proven than other possible explanations. Indeed, Lam and colleagues ${ }^{8,9}$ found significant benefits of cognitivebehavioural therapy for bipolar disorder after controlling for medication adherence. Gupta \& Brown are right to point out that there are no drug-free studies of psychological interventions in bipolar disorder. Such studies prove an enormous challenge, given the present readiness to prescribe. However, it is encouraging that psychological therapies appear to be superior to medication in the long term for a range of other psychiatric disorders, including unipolar depression, post-traumatic stress disorder and panic disorder. ${ }^{10,11}$ Nevertheless, our approach sees a key role for medication in services, particularly in situations of acute risk, and for clients for whom the benefits are clear. The authors correctly note that we omitted reference to trials by Scott et al ${ }^{12}$ (which had negative results) and Miklowitz et $a^{13}$ (which had positive results). This we will address when the report is updated, but it does not significantly change the conclusions of the report (nor did it affect the NICE guideline recommendations on psychological therapy ${ }^{5}$ ). The authors suggest that the evidence informing the report is limited. We disagree. In addition to the trials and experimental research that is covered, we provide extensive reports from large numbers of people with bipolar disorder, reporting on how they have learned to cope with their mood swings. We regard such evidence as primary rather than secondary in the pursuit of a scientific understanding of emotion regulation and how it becomes a problem for many people, just as early psychiatrists utilised a phenomenological stance in building their initial categorisations of mental illness. We welcome the opening of a debate on these issues and look forward to further constructive discussions.

\section{Declaration of interest}

All six authors are also authors of the report that is the topic of this letter.

1 Gupta S, Brown J. Psychological therapies for bipolar disorder - adjunct not alternative to pharmacological treatments. Psychiatrist 2011; 35: 196

2 British Psychological Society. Understanding Bipolar Disorder - Why Some People Experience Extreme Mood Swings and What Can Help. British Psychological Society, 2010.

3 Syrett M. A balanced approach to bipolar. Pendulum 2010; 26: 2.

4 American Psychiatric Association. Diagnostic and Statistical Manual of Mental Disorders (4th edn, text revn) (DSM-IV-TR). APA, 2000

5 National Collaborating Centre for Mental Health. Bipolar Disorder: The Management of Bipolar Disorder in Adults, Children and Adolescents in Primary and Secondary Care (NICE Clinical Guideline 38). National Institute for Health and Clinical Excellence, 2006.

6 Beynon S, Soares-Weiser K, Woolacott N, Duffy S, Geddes JR. Psychosocial interventions for the prevention of relapse in bipolar disorder: systematic review of controlled trials. Br J Psychiatry 2008; 192: $5-11$.

7 Scott J, Colom F, Vieta E. A meta-analysis of relapse rates with adjunctive psychological therapies compared to usual psychiatric treatment for bipolar disorders. Int J Neuropsychopharmacol 2007; 10: 123-9.

8 Lam DH, Watkins ER, Hayward P, Bright J, Wright K, Kerr N, et al. A randomized controlled study of cognitive therapy for relapse prevention for bipolar affective disorder: outcome of the first year. Arch Gen Psychiatry 2003; 60: 145-52.

9 Lam DH, Hayward P, Watkins ER, Wright K, Sham P. Relapse prevention in patients with bipolar disorder: cognitive therapy outcome after 2 years. Am J Psychiatry 2005; 162: 324-9.

10 Butler AC, Chapman JE, Forman EM, Beck AT. The empirical status of cognitive-behavioral therapy: a review of meta-analyses. Clin Psychol Rev 2006; 26: 17-31.

11 Barlow DH, Gorman JM, Shear MK, Woods SW. Cognitive-behavioral therapy, imipramine, or their combination for panic disorder. JAMA 2000; 283: 2529-36.

12 Scott J, Paykel E, Morriss R, Bentall R, Kinderman P, Johnson T, et al. Cognitive-behavioural therapy for severe and recurrent bipolar disorders. Randomised controlled trial. Br J Psychiatry 2006; 188 313-20. 
13 Miklowitz DJ, Otto MW, Frank E, Reilly-Harrington NA, Kogan JN, Sachs $\mathrm{GS}$, et al. Intensive psychosocial intervention enhances functioning in patients with bipolar depression: results from a 9-month randomized controlled trial. Am J Psychiatry 2007; 164: 1340-7.

Steven H. Jones, Professor of Clinical Psychology, Spectrum Centre for Mental Research, Lancaster University, UK, email: s.jones7@lancaster.ac.uk; Fiona Lobban, Anne Cooke, Warren Mansell, Kim Wright and Joanne Hemmingfield, Spectrum Centre for Mental Research, Lancaster University doi: 10.1192/pb.35.11.432b

\section{The private sector v. the NHS: who's the good, the bad and the ugly?}

For psychiatrists who care for National Health Service (NHS) patients in the private and voluntary sectors, it can sometimes be dispiriting when colleagues make inclusive overtures, but manage at the same time to vent their spleen about the independent sector. Alistair Stewart, in the September lead correspondence item in The Psychiatrist, ${ }^{1}$ admits that there is 'the good, the bad and the ugly' in all sectors, and even that there are 'flagship private sector providers', but only lists recent quality failures linked to the activities of private equity groups. He would want to eschew the term independent sector as a 'polite fiction', preferring frankness such as 'the private sector milking the money which most taxpayers think is going to the $\mathrm{NHS}^{\prime}$. Are independent charitable providers and all wellmeaning professionals outside the NHS to be tarred with the same brush?

Similarly, in response to an editorial I co-authored, ${ }^{2}$ another NHS psychiatric colleague ${ }^{3}$ gives an unbalanced view, focusing on fraud in US healthcare, the profit motive and sharp practice, contrasting this with the NHS, which is apparently an example of 'a system based on trust and common purpose'. Is the truth not that in-house NHS services across the country include both shining examples of excellence and dedication, and scandalous failures of care and management - just as much or as little as many other kinds of organisation?

It is important to see that all sectors have been caught up in the same economic cycle. In the boom years the for-profit, commercial sector brought major investment in modern hospitals and community homes, from which NHS mental health patients have greatly benefited. Many would otherwise be homeless or in prison. The ultimate source of this commercial investment is mostly the savings of ordinary people, funnelled through investment funds of various sorts. Of course this was boosted by irresponsible borrowing, leading now to an intense resource squeeze, to unacceptable quality failures, and to investors making substantial losses.

All this parallels huge government investment in health services in recent years, the consequent public debt, and now severe reductions in spending, especially in social care. Mental health patients are among the vulnerable people affected, as care providers, including many community mental health charities, struggle to survive. Charities have to learn lessons from and compete with state and commercial provision, despite being challenged by the downturn through little fault of their own.

I would encourage NHS colleagues to acknowledge good work done by psychiatrists and mental health workers in every sector, in the best interests of patients, and balance their critical comments with examples of poor clinical practice wherever they arise. It is painful to see the fallout of the international debt crisis roll through our society and affect the most vulnerable. The responsibility rests perhaps with key decision makers in international public and private finance, but let us not become so conflicted that we waste our energies blaming each other in the mental health world.

\section{Declaration of interest}

St Andrew's is the UK's largest provider of charity sector services to the NHS.

1 Stewart AG. The NHS, the private sector and the future. Psychiatrist 2011; 35: 354

2 Sugarman P, Kakabadse A. Governance, choice and the global market for mental health. Int Psychiatry 2011; 8: 53-4.

3 Bernadt $M$. The English market model is not fit for export. Int Psychiatry 2011; 8: 55-6.

Philip Sugarman CEO and Medical Director, St Andrew's Healthcare, Visiting Professor, School of Health, University of Northampton, Honorary Senior Lecturer, Institute of Psychiatry, King's College London, St Andrew's Healthcare, Billing Road, Northampton NN1 5DG, UK, email: psugarman@standrew.co.uk

doi: $10.1192 /$ pb.35.11.434

\section{A response to Professor Sugarman}

Professor Sugarman's response to my letter in the September issue helps to clarify a number of points.

First, to deal with sentimental matters. I am sure that all well-meaning professionals outside and inside the NHS have honourable motives and are committed to their patients. However, this is not the real issue. We do not live in the 'mental health world' but in a world where the future of the NHS is being threatened by large private sector organisations keen to promote and benefit from certain policy changes. These, in the guise of promoting 'choice', will enable them to take large bites out of the NHS and establish the profit motive as the dominant force in healthcare in the UK, just as it already is in the USA. These organisations have been frustrated for a long time by the fact that the existence of the NHS in Britain has restricted opportunities for them. Emails made public this summer, sent by David Worskett, head of the amusingly named NHS Partners Network (representing groups such as UnitedHealth, Care UK, BUPA, the General Healthcare Group and Ramsay Health (are UK), demonstrate the determination of these companies to establish their bridgehead into the NHS.

Professor Sugarman says that the NHS is 'apparently [my emphasis] an example of a system based on trust and common purpose'. He may well find that very large numbers of people working in the NHS and using it see it in exactly that way, for all its failings.

Professor Sugarman seems keen in his letter to distinguish 'independent charitable providers' from the 'for-profit, commercial sector'. However, in the article he wrote with Professor Andrew Kakabadse in International Psychiatry, he appears quite ready to argue on behalf of 'providers with international experience' and 'the power of globalisation of markets and information' to promote 'improved care through choice for patients'. ${ }^{2}$ Is this how the charitable sector sees itself?

There are signs that some leaders of the charitable sector are smoothing the way for private sector organisations. The 